founded with imperforate hymen; this is an occlusion of the lower portion of the vagina immediately behind the hymen. This occlusion is of embryonic origin, and is caused by defective development of the lower portion of Müller's ducts, and is sometimes improperly described as a double hymen. More frequently, however, it is overlooked or mistaken for the hymen itself, from the fact that it is pressed forward by the accumulated blood in hæmatometra and hæmatokolpos, and lies almost in immediate contact with the hymen.

I will state the following conclusions:

Ist. Nearly all the malformations of the female sexual organs, previous to puberty, result from arrest of development.

2nd. As the upper and lower portions of Müller's ducts develop independently of each other, we may find the ovaries developed without the uterus, and vice versa.

$3^{\text {rd. Perfect development of the external genital }}$ organs and the mammary glands does not preclude defective development of the vagina, uterus or ovaries.

4th. Entire absence of the uterus or the ovaries can only be determined by post-mortem examination or by laparotomy.

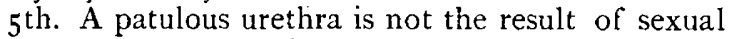
intercourse through this organ, but is caused by arrest of development.

6 th. In congenital atresia of the vagina a patulous wrethra is the rule, in acquired atresia it is the exception.

\section{REMARKS ON THE SURGICAL TREATMENT OF THE MALIGNANT DISEASES OF THE UTERUS.}

\author{
BY WM. H. BYFORD, M.D., CHICAGO.
}

Presented to Section of Obstetrics and Diseases of Women of American Medical Association, May, 1884 .

The malignant diseases that more frequently attack the uterus are :

Ist. Epithelioma.

2nd. Medullary carcinoma; and

$3^{\text {rd. Sarcoma. }}$

They occur, according to my observation, in the order of frequency here mentioned.

Probably not less frequently than the sarcoma is found the epithelial or corroding ulcer. Preparatory to the surgical treatment of these affections I desire to make some observations, particularly as to the tissues first invaded by them, their mode of development and manner of destruction. My idea of an (pithelioma is that the deposit occurs on the free surface of the mucous membrane, in its epithelial stratum, and consists essentially of extreme multiplication of epithelial cells which, after great development of the tissue in which the process is going on, die, causing sloughs of greater or less size.

This form of malignant disease (call it cancer or cancroid, as you please) is located so that the comparatively dense mucous membrane is between it and the more vascular uterine tissues; hence its cells do not readily find their way into the circulation, and it is at first, and long remains, a local affection.

Another peculiarity is that it does not, until quite late, and sometimes it never destroys the deeper portions of the viscus by ulceration.

The direction is to the surface, and the process of necrosis destroys the superficial morbid growth. The disease is one in which the morbid advancement is away from, instead of into, the substance of the organ.

The second variety of malignant disease of the uterus consists in a great multiplication of cells in the lymph spaces beneath the mucous membrane, which are the terminal cavities of the lymphatic vessels. These cells are probably the epithelial cells of the endothelium of these terminal lymphatics. The deposit is therefore behind the mucous membrane, and really has no barrier to resist the entrance of its cells into the lymph current. This circumstance allows of the early migration of the morbid material to the neighboring and even distant organs, almost as early as they commence formation.

These features of the locality of the deposit are the cause of its greater malignancy, and have given rise to the notion that it is of general instead of local origin. There undoubtedly occur cases in which both varieties coexist from the commencement.

Necrosis in the second variety is caused by the distension of the lymph spaces until the small bloodvessels are strangulated by pressure, and nutrition in the mucous membrane to which they are distributed is arrested.

Small sloughs are detached and thus ulceration is inaugurated which continues till all the invaded tissues are destroyed or the patient dies.

In the third variety of malignant diseases-sarcoma-the cells are generated in the fibrous or connective tissue outside the lymphatics, both in the substance of the cervix and its mucous membrane.

The migration or dissemination of the cells in sarcoma is not so easy or early as in the second, but is more so than in the first variety.

If I am right in this explanation of the difference in the origin and progress in the morbid processes of the malignant diseases of the uterus, it will not be difficult from it to determine the cases to which radical surgical proceedings are applicable, and in which the prognosis under treatment is more or less favorable. I believe that curability is sometimes possible in the first and never in the second or third varieties, but in all, surgery constitutes the most effective means of palliation. There are some cases of epithelial cancer that may be effectually extirpated, and a complete cure accomplished.

A regard for truth requires it to be said, however, that the curable cases of epithelioma are a small minority ; but on the other hand it may be said that in a majority of cases life may be much prolonged, and great comfort secured while the patient lives.

Almost all of them are, therefore, proper subjects for surgical treatment. Believing that in this variety 
alone a complete removal is practicable, how shall we operate?

If removal of the whole uterus either per vaginam or through the abdominal walls is ever justifiable, the operation should be confined to this variety.

The mortality from this operation is, I think, too great, however, for it ever to gain admission to the category of legitimate operations. The statistics of extirpation of the uterus for cancer have been recently successfully appealed to by Dr. J. Reeves Jackson as evidence that the operation is not justifiable. ${ }^{1}$ He very properly concludes that extirpation of the cancerous uterus does not lessen suffering, and it shortens the aggregate of life.

It must be stated, however, in this connection, that the statistics are of much less value than they might be; for while the danger of the operation is the same in all forms; on account of want of discrimination in the reports of the kind of cancer operated upon we cannot judge what. the success would be if it was practiced for the epithelial variety alone.

If extirpation is to continue in favor with reckless surgeons it is to be hoped that in future more care will be taken in reporting particularly the nature or variety of the cancer operated upon.

It will then be seen, I have no doubt, that the successes will be on the side of peripheral or epithelial cancer, and the greatest number of deaths will range themselves under the head of interstitial or medullary cancer. I feel assured, however, that more observation will cause the operation of extirpation to be expunged from the future list of operations for cancer of the uterus.

The late Dr. J. Marion Sims, as in many other instances of uterine surgery, took the lead in the appropriate radical treatment of cancer of the uterus. ${ }^{2}$

It is to be regretted, however, that he did not sufficiently indicate the variety of cancer in which he operated, to enable us to know in what cases his process was successful.

Notwithstanding this defect in his reports, to him must be accredited the greatest improvement in the treatment of cancer ever yet made, and in his method we can see the first scientific and successful effort at a radical cure of this almost incurable disease.

In one case of which $I$ was personally cognizant of epithelial or peripheral cancer, he operated over ten years ago, and the patient is now living and apparently free from the disease. His method has since been resorted to by many operators, and, as might have been expected, with varying success, for no surgical procedure will invariably insure a cure in what would seem the most favorable cases.

His method has been modified to some extent by those who have followed him.

It consists in cutting away the whole cervix and as much of the body as will insure the removal of all the disease accessible, followed by thorough and deep cauterization of the whole excised surface. In some cases, as in the one above, this treatment will eftect a cure. To perform this operation easily, the patient

\footnotetext{
1 Gynzecological Transactions for 1883 .

2 American Journal of Obstetrics.
}

should be placed on her back, with the hips brought down so as to project slightly over the end of the table, with the limbs flexed over the abdomen (Simon's position), and the perinæum drawn well back. After this preparation the cervix should be seized by both lips if possible, with a vulsellum, and depressed until considerable tension is apparent-no more force than this is necessary or permissible-and an incision made with the knife or scissors through the mucous membrane at the junction of the vagina and cervix, so as to entirely encircle the latter.

Through this circular-incision the neck and body of the uterus may be enucleated to any desirable extent. The connective tissue between the bladder and uterus and the peritonæum covering the uterus is so loose that proper care will enable us to separate the latter from its investments, and the portion of the uterus thus isolated may be cut away. When we are successful in removing half or two-thirds of the uterus from its peritoneal investment it is not proper to apply any caustic, as it would be likely to penetrate the bladder or peritoneal cavity.

It is, however, quite advisable to apply the hot iron to the stump of the uterus, for the double purpose of checking the hæmorrhage and destroying the tissue to a still greater depth.

The iron must be below red heat, or else neither of these objects will be accomplished.

If any considerable hæmorrhage attend or succeed this operation, the cavity should be filled with cotton saturated in a solution of Monsel's iron half strength. This operation is applicable to cases where the disease has not invaded the cavity of the uterus to any considerable extent.

But there are cases where the mucous membrane of the cervix and body is the subject of epithelial degeneration while that covering the external portion of the neck is not affected. The disease is then not generally curable except by complete extirpation of the organ. It may sometimes, however, be effectually removed in its early stages by excavation with the curette and caustics. Later, when the fibrous structure of the organ is softened by the deposit, this cannot be done. The object of the operation is to remove the zhole mucous membrane with the deposit, and it will require great care to do this. The uterus should be drawn down and fixed with the forceps by seizing the posterior lip, and then a small sharp curette introduced to the fundus, and by forcibly carrying its sharp edge over the whole surface first in one direction and then another until the tissue removed is entirely free from the morbid deposit.

It will often be best to use larger curettes as the scraping proceeds. Judging from my own observation there is not much danger of cutting through the wall of the uterus when the case is one of epithelial degeneration of the mucous membrane instead of cancerous degeneration of the parietes. The latter kind of deposit renders the tissues friable and they break down under the curette. In the cases of pure epithelioma as I have defined the affection, that friability does not exist, and if we go through the wall it is by using too much force.

After we have thus thoroughly removed the disease 
from the cavity we should increase the probability of a cure by the introduction of a caustic.

This part of the operation should also be done with a thoroughness that attacks every portion of the cavity.

For this purpose I think the acid nitrate of mercury the best caustic. Small pellets of cotton saturated with the acid, afterwards squeezed as nearly dry as possible, and if prepared several days before used so much the better.

Each one of these should be well secured by strong thread, that they may be easily removed.

The uterine cavity should be packed full of these and then the vagina should be filled with absorbent cotton pressed well up against the cervix.

Chloride of zinc, nitric acid or bromine may be substituted for the acid nitrate, but I believe the mercury in this latter preparation adds to its efficacy.

When we use the caustic in the scraped cavity we should remove it in about twenty-four hours and then keep the parts clean by irrigation.

If there is any return this operation may be repeated as frequently as necessary. In some instances where I have repeated this operation two or three times, I have found the uterine cavity becoming smaller each time. The diseased surface therefore becomes less after each successive operation.

In an excellent paper published in the American Journal of Obstetrics for April, I882, Dr. W. H. Baker, of Boston, gives a flattering account of his success with the operation for the removal of a part of the uterus, per vaginam.

He reports six cases in which after the lapse of five years there was no return; so they are probably entirely cured, and that in thirty cases he has had no deaths.

This encouraging report establishes the efficacy and safety of the operation when skilfully done.

While I fully accord to Dr. Baker great credit for his labor in this direction, I must be allowed to complain that he has not been sufficiently definite in the description of his cases to enable us to distinguish between those in which the disease began in the mucous membrane, and such as were of interstitial origin; and I protest that no such success can be attained where the deposit was located in the fibrous structure of the uterine walls. I wish also to disclaim any pretension that even in the earliest stages of development all these cases can be cured.

I only desire to be understood as believing that it is the most promising and safest method of treating the disease when confined to the mucous membrane, without any considerable tumefaction and distortion of the cervical parenchyma. My own cases are not very numerous, but among them I think I can count at least six cases of success, and more, in which I have strong hopes that there will be no return of the disease.

In almost all cases and all kinds of malignant diseases of the uterus, surgery is the important palliative means.

While hæmorrhage, pain, mental worry and other conditions contribute to the general result in cancer of the uterus, nearly all the sufferers die of septicæmia.

The absorption of putrid material connected with the process of necrosis or sloughing of the tissues invaded by the deposit, so poisons the blood that septic fever is sure to be established.

The septic symptoms are influenced in their intensity by the amount of sloughing, and the power of resistance afforded by the constitutional condition of the patient. Usually almost no symptoms present themselves during the time the deposit is going on. When the tissues commence to break down the cancerous cachexia begins to show itself, and cancerous cachexia simply means septicæmia. Its peculiarity depends upon the fact that it is slowly established. When once established it gradually increases in severity until the patient succumbs to its exhausting influence.

In interstitial cancer we may alleviate the symptoms by removing the sloughing surface by the free use of the sharp curette. In many instances where the sloughing surface is large and the sanious discharge very great, shaving off the entire necrosed substance down to the living tissue will arrest the septic symptoms so completely, and relieve the suffering to such a degree, as to inspire the patient with hopes of recovery.

The operation of curetting should be resorted to early and repeated frequently, until the destruction of the organ is so great as to render it impracticable.

The process of removing the necrosed tissue with this instrument, is simple and free from danger. If the cutting is carried only far enough to get away the sloughs down to the underlying living tissue, no blood-vessels will be severed large enough to give rise to serious hæmorrhage.

Probably the greatest danger consists in tearing through into the peritoneal cavity, and wounding the bladder, ureters and rectum. In the advanced stages of the disease, when the deposit extends to these parts, such accidents may be rendered imminent.

They may for the most part be avoided even then, and until far advanced they may always be avoided. Such accidents usually occur as the result of too much pressure upon the instruments, and the effect is not so much by cutting as by tearing the tissues rendered friable by the existence of the deposit in them. The curette should therefore be very sharp, and it must be applied so lightly that the process is one of cutting only.

The instrument ought to be very small as well as sharp, so that it may be carried with facility into all minute sulci of the affected parts.

Every part brought under the instrument must be plainly visible, and the whole operation should be guided by the eye. This may be best accomplished by dilating the vagina well with Simon's instruments and allowing a stream of water to forcibly run into the cavity through an elastic hose connected with an elevated fountain. This current of water, if well directed, will wash out the clots and sloughs so completely that we can all the time see the depth and extent to which the strokes of the instrument extend. I must insist that this operation, thus lightly and 
thoroughly done, may be executed without giving the patient any considerable inconvenience, and also that it ought to be often repeated from the time the septic symptoms begin until the sloughing parts can no longer be reached.

I believe that caustics cannot be made half as effi. cient for this purpose as the curette. The process of curetting the surface of the superficial cancer for removing the sloughing material is also the most efficient means of palliating the symptoms when they cannot be cured. Of course I do not wish to ignore the value of disinfectant applications as palliative measures. After curetting, and sometimes without it, the free and frequent application of the muriated tincture of iron will often so disinfect the surface as to keep in abeyance the septic symptoms for a long time.

The value of this remedy I believe was first taught by the late Sir James Y. Simpson, and so greatly did he esteem the application that he believed in certain cases the advance of the disease might be arrested for an indefinite period.

\section{SUMMARY.}

Ist. The more common forms of malignant diseases of the uterus are :

(a) Epithelial or superficial cancer, commencing on the free surface of the mucous membrane.

(b) Interstitial (medullary) cancer, commencing in the fibrous structure, the deposit being within the lymph spaces.

(c) The coexistence of these two varieties.

(d) Sarcoma, in which the cells are mingled with the fibres of the connective tissue.

and. The superficial cancer can often be removed and consequently cured.

(a) By ablation of the cervix and as much of the body as necessary.

(b) When affecting the mucous membrane of the whole cavity, by thoroughly and repeatedly curetting all the morbid deposit away and cauterizing with acid nitrate of mercury, bromine or chloride of zinc.

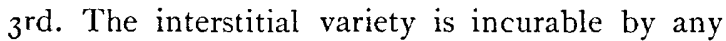
method of operation or by any means.

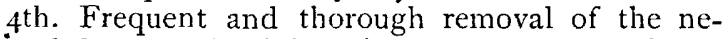
crosed down to the living tissue by the curette is the most efficacious of palliative measures in the latter variety.

\section{POLLUTION OF THE UPPER OHIO, AND THE W A TER-SUPPLY OF THE CITIES AND CHIEF TOWNS WITHIN THE FIRST HUNDRED MILES OF ITS COURSE.}

BY JAMES E. REEVES, M.D.,

SECRETARY OF THE STATE BOARD OF HEALTH OF WEST VIRGINIA.

Read before the American Public Health Association, at the meeting in St. Louis, October 16th, 1884 .

The condition of health and probable duration of life of a people may be correctly measured by the quality and quantity of their water-supply. Indeed, good health can as little be supported without pure water as without pure air ; therefore, of all the diversified and complex relations which man bears to surrounding influences, none are more important than that which relates to the water-supply of the locality in which fortune has placed him.

Considered either in his physical, social, moral, industrial, or political relation, the subject is of transcendent importance, for it involves the main questions of success in life. If he take up his abode in the midst of unsanitary surroundings, the inevitable sequence will be a correspondingly unfavorable influence upon his destiny - a check upon his prosperity, and a blight, more or less serious, upon all those attributes which are usually considered essential to his well-being and happiness.

As a natural corollary, the community which is ignorant or regardless of its sanitary surroundings and vital history, is but feebly defended against " the pestilence that walketh in darkness, and the destruction that wasteth at noonday ; "for the wholesome lessons of domestic and civic hygiene afford to such a people no rules and defenses for the person, the domicile, the municipality and the State, nor encouragement to the general prosperity in stimulating the practical applications of science and art, commercial enterprise, manufactures, and popular intelligence. All these are at a low standard, while frequently recurring endemic and epidemic diseases, and a high death-rate, constitute the most prominent features of their culpable history.

River pollution from sewage and other supplies of refuse and corruption in towns and cities has assumed such fearful proportions that the question presses itself upon wise men and sanitarians - " Is industry free to tumble out whatever horror or refuse it may have accumulated into the nearest crystal brook, regardless of gods and men, and little fishes; is free industry free to convert ail our creeks and rivers into sewers?" "It is ours," says Dr. Gairdner, "to use air and water, and then pass them on; but woe to the man or the community that detains or imprisons these his servants of the hour in their further execution of God's endless work!'”

With these introductory reflections, I now submit the following brief statement of facts relating to the water-supply of the cities and chief towns situated on the banks of the Ohio River within the first hundred miles of its course.

Commencing at the head of the Ohio, there are two cities-Allegheny and Pittsburgh-whose aggregate population is not less than 240,000. Next, Rochester, Pa., a town of 3,500 population; next, East Liverpool, O., with a population of over 6,000 ; next, Wellsville, O., with a population of 4,500; next, Steubenville, O., with a population of 14,000 ; next, Martin's Ferry, O., opposite Wheeling, with a population of 4,600 . On the West Virginia shore, between Wheeling and Pittsburgh, the principal towns are New Cumberland, with a population of $\mathbf{I}$,500 , and Wellsburg, I 6 miles distant from 1 Wheeling, with a population of 2,000 ; next, Wheeling, with a population of $3^{\mathrm{r}, 500}$; next and last, Bellaire, O., with a population of ro,000. 